the more aggressive blue-black males of the neighbourhood. This was proved by checking the movement of diamond-scratched fragments of blue glass from bower to bower.

Territorial aggression and the capacity to collect and to retain by active intra-specific competition appropriate display things confers a high probability that a given blue-black male will breed. Despite the domination of mature blue-black males over the grey-green younger ones during the sexual season, no evidence is yet available that polygamy occurs. Nests of Pt. violaceus are hard to find, and in dense forest it is extremely difficult to connect a nest with a bower, for the conspicuous male apparently takes no part in nest-building, incubation or the rearing of the young. There is histological evidence that the male is potentially polygamous. After shedding spermatozoa the testes of monogamous species collapse and the seminiferous tubules undergo a massive fatty metamorphosis ${ }^{2}$. Two blue-black males, collected while displaying at bowers in December (two months after fertilization date), still possessed testes of about maximum size. These were packed with bunched spermatozoa. Spermatogenesis was still actively proceeding and only the first signs of fatty metamorphosis showed. The remarkable continuation of male interest in the display ground is therefore accompanied by an apparently undiminished capacity for reproduction. It is only when the female and young appear in the bower-territory in January that the male display discontinues and the testes collapse. The blue-black owner of the bower and a party of green-grey birds (up to half a dozen in number) disport themselves about the playground and then leave the territory to join communal, nomadic feeding flocks which noisily range through the fruit-trees. The normal number of eggs per clutch is one to three.

It is not known what are the external stimuli that influence the breeding cycle and cause the males to take up territory as early as mid-winter, though it is probably advantageous for an individual to gain territory early. There appears to be no change in the frugivorous diet at the time the flocks break up. In captivity, Pt. violaceus eats insect food all the year if it is made available. However, experiments show that it does not scratch aside leaves or other debris under which insects or land crustaceans take refuge. Again, it makes no attempt to open a transparent cocoon through which a motionless organism is clearly visible. It will, however, pursue flying insects ${ }^{3}$. Hirst ${ }^{4}$ has evidence that suggests that captive satin bowerbirds are unable to bring young to maturity on a largely non-protein diet even though they bred several years in succession. Whatever are the factors that delay ovulation until late September or October, it is clear that the delay ensures that the young will be launched at the time of year when the forest is full of flying insects. 'Sudden flushes' of bogong moths (Agrotis infusa) occur during September and October, and swarms of winged termites (Coptotermes lacteus and $C$. acinaciformis) suddenly appear from September to February. Towards the end of October cidadas emerge in millions, and the following month enormous numbers of 'Christmas'-beetles (Anoplognathus spp.) appear*. Although the territory habit spreads the bowerbird population over the available forest, there

- Phenological data have been kindly supplied by Mr. Anthony Musgrave, Curator of Entomology, Australian Museum, Sydney, and operative assistance has been had from Mr. J. Newcombe and Dr. A. Bollinger. seems no obvious connexion between bower-territory and food supply. Both sexes gather food in common ground outside the sphere of bower-influence.

The odd visits of males to their territories during the post-nuptial flocking season when the gonads are small offers no support for the hypothesis that bowers are primarily 'recreational' in function. Howard ${ }^{5}$ has shown that it is general for many British species to visit their territories in winter, and Morley ${ }^{6}$ has listed about seventy birds that show autumn or winter sexual behaviour. Again, there is now evidence ${ }^{2}$ (and Marshall and Coombs, unpublished) that the avian testis, in autumn and winter, is not necessarily inactive but has become regenerated in the lipoid and cholesterol content of its interstitial cells. This regeneration enables the production of a season's second brood in some species and may be correlated with the post-nuptial display that is so widespread among birds.

At the same time, it is not at present suggested that bowerbirds do not get pleasure from their vocal mimicry of other species, from their extraordinary gyrations at the display grounds and from the colours of the objects that they bring to them. No opinion at present can be offered as to the function, resthetic or otherwise, of a final remarkable habit : that of painting or plastering the inner walls of the bowers with a mixture of charcoal and saliva or with fruit-pulp. Some writers have claimed that $P t$. violaceus shows in this connexion intelligence and "deductive reasoning". The habit is common only at the time of spermatogenesis.

Experimental work is being continued in Great Britain.

1 Marshall, A. J., Nature, 153, 685 (1944).

"Marshall, A. J., Quart. J. Micro. Soc., 90, 263 (1949).

3 Chaffer, N., The Emu, 30, 279 (1931).

4 Hirst, A., Vict. Nat., 58, 7 (1940).

"Howard, E., "Territory in Bird Life" (London, 1940).

'Morley, A., The Ibis, 85, 132 (1943).

\section{METALLURGICAL APPLICATIONS OF THE ELECTRON MICROSCOPE}

A

VALUABLE and stimulating symposium on 1 metallurgical applications of the electron microscope was held in the Lecture Theatre of the Royal Institution on November 16, 1949. The meeting was organised by the Institute of Metals in association with seven other learned societies. The president of the Institute of Metals, Sir Arthur Smout, was the chairman for the morning session, and in the afternoon the chair was taken by Dr. F. C. Toy, president of the Institute of Physics. The sessions were well attended by a representative international gathering of electron microscopists and by metallurgists interested in this new technique for the study of metals. Following the usual practice of the Institute of Metals, copies of all the contributed papers were available before the meeting, and summaries of the papers to be discussed at each session were presented by rapporteurs-by Dr. V. E. Cosslett at the morning session, and by Dr. N. P. Allen at the afternoon session. A large part of each session was therefore available for discussion.

In the papers presented during the morning session, the emphasis was mainly on technique. The opening paper, by Dr. N. P. Allen of the National Physical Laboratory, considered very briefly the 
historical background and the development of the electron microscope to the stage where it has become a useful metallurgical instrument. It was written from the point of view of the metallurgist, and concluded with a formidable list of metallurgical problems awaiting solution where the electron microscope might prove to be a valuable tool. Electron microscopy in France was represented by Prof. P. Grivet, of the Sorbonne, who surveyed the development of the instrument and of the techniques employed with particular reference to the C.G.T.S.F. electrostatic instrument, in the development of which he has played a large part. After a brief account of the application of the microscope to the study of small particles and to metallurgy, the author described some recent developments of emission and scanning microscopes in France.

The paper by Dr. H. Mahl, unfortunately very brief, was little more than a catalogue of the work carried out in Germany during and since the War. An interesting micrograph of a fractured steel surface obtained by the aluminium pressing method was shown, and in view of Dr. J. Nutting and Dr. Cosslett's contribution on the same topic, one would have liked to have heard more of this work. These authors have made certain modifications of the method, and have produced results which are comparable with those of Mahl. The results are of a preliminary character and show promise of providing valuable information on the process of fracture. In a second paper, Drs. Cosslett and Nutting, of the Cavendish Laboratory, Cambridge, described an investigation of the influence of etching conditions on the stripping of 'Formvar' films of different thicknesses from pearlite and sorbite in a range of carbon steels. The sixth paper in the morning session, by Dr. G. L. J. Bailey and Miss S. Vernon-Smith, of the British Non-Ferrous Metals Research Association, was concerned principally with the study of non-ferrous alloys, preceded by a survey of replica methods and some of the artefacts which may arise in plastic replicas. They have studied grain-boundary structure in $\beta$-brasses containing aluminium, grain-boundary precipitation in aluminium-magnesium alloys, and several other aluminium alloys. $\gamma$-Phase was shown to be precipitated in the grain boundaries of the high-tensile brasses which are subject to brittle fracture. Dr. C. M. Schwartz contributed an interesting and valuable survey of the methods employed in the United States for the examination of metal surfaces by electron microscopy and of some of the results that have been obtained.

In introducing these papers, Dr. Cosslett considered briefly the rapid development of the electron microscope in the past fifteen years and compared it with the development of the X-ray diffraction technique. He thought that any new instrument or technique goes through three stages-development, use in research laboratories, acceptance as a technological tool. For example, the $\mathrm{X}$-ray method is now widely used in research and as a tool for the control of technological processes. The electron microscope seems to have reached the second stage in its history, and, provided that certain prejudices can be overcome and that every care is taken to establish confidence in the instrument, there is no reason why it should not pass on to the third stage. The discussion was opened by Prof. G. I. Finch, of the Imperial College of Science and Technology, with an appeal to electron microscope users to avoid scientific myopia, to treat the electron microscope as an aid to research to be used in conjunction with other methods and to leave the design of instruments to the makers and to electron opticians. He thought that much of the controversy over the interpretation of results could be overcome by suitably planned and often simple experiments; in particular, he was critical of the attention given to hypothetical explanations of artefacts arising in plastic replicas. By way of answering some of Prof. Finch's criticism, Dr. Bailey elaborated the discussion of artefacts in his paper and gave an expression relating film thickness to the viscosity of the plastic solution and the time after withdrawing the specimen from the solution. Mr. J. Trotter, of the National Physical Laboratory, directed attention to some of his recently published results which establish that artefacts can arise in the way postulated by Bailey and Cosslett, but also show that these effects may not always be introduced by the replica.

There was a lively discussion of the micrographs of pearlite illustrated in Dr. Nutting's paper and of an aluminium pressing replica of the same material, in which Dr. W. Hume-Rothery, Dr. Allen, Dr. Cosslett and Dr. A. F. Brown joined. Dr. Allen mentioned some work carried out at the National Physical Laboratory by Messrs. F. W. Cuckow and J. Trotter in which the transformation of a steel at about $400^{\circ} \mathrm{C}$. has been studied by phase-contrast microscopy, and by the plastic and silica replica processes in the electron microscope. The results are such as to give confidence in the plastic replica process. Prof. Grivet referred to the advantages of dark-field illumination in certain cases, particularly where it is desired to distinguish between amorphous and crystalline material. As an example, he projected a micrograph of a thin section of rubber prepared by normal illumination and another prepared with dark-field illumination. In the latter, the crystalline particles of zinc oxide could be clearly seen. The limitation of resolution imposed by the molecular size of such materials as polystyrene and 'Formvar' was raised by Prof. Finch, who said that it had perhaps been inferred that there was no such limitation with aluminium oxide replicas, and he questioned the accuracy of this inference. Could it be assumed that the aluminium oxide is formed in the molecular state? Mr. Agar mentioned the pre-shadowing technique which has proved valuable in the biological field, and he said that he has had some limited success in applying it to metallurgical studies.

The papers discussed in the afternoon session were concerned mainly with metallurgical investigations rather than with the technique of electron microscopy. The paper by Messrs. Trotter, D. McLean and C. J. B. Clews, of the National Physical Laboratory, described an examination of the microstructures of a series of iron-carbon alloys. 'The electron micrographs reveal detail beyond that visible with the light microscope. An important feature of the work is the wide variety of microstructures which can exist in a specimen of given carbon content. Dr. F. Keller, of the Aluminium Co. of America, reviewed the various methods of specimen preparation used in the study of light alloys, and some of the results obtained. It appears that the 'critical size' of precipitate particles to obtain optimum strength or hardness in age-hardening light alloys varies appreciably with the type of alloy and the hardening constituent. In an aluminium-magnesiumsilicon alloy the particles are $0.02 \mu$ in size, while for a fully aged aluminium-silver alloy they are as large 
as $\mathbf{0 . 5} \mu$. Messrs. G. L. Bucknell and G. A. Geach, of the Associated Electrical Industries Research Laboratory, have also studied age-hardening, in this case in an aluminium-1 per cent copper alloy using the oxide replica process. They show an interesting series of micrographs, including two which purport to show plate-like precipitation after ageing at room temperature.

The slip processes in aluminium were the subject of a contribution by Dr. A. F. Brown, of the Cavendish Laboratory, Cambridge. He has extended the elec. tron microscopic investigations of Heidenreich and Shockley to the study of deformation at temperatures from $-180^{\circ}$ to $500^{\circ} \mathrm{C}$. He found that at all temperatures the slip zones seen in the light microscope could be resolved into elementary slip lamellæ, and that the width of these lamellæ and the amount of slip do not alter with temperature, the only difference being in the grouping of the lamellæ. The lamellæ were 200-800 A. thick and the slip distances were 1600-2200 A., the higher values in both cases being found at higher temperatures. Nickel-chromium alloys used in heater elements were examined by Messrs. B. S. Cooper and G. A. Bassett, of the General Electric Co. They found that the methods of specimen preparation used in optical microscopy were unsuitable, and it was therefore necessary to study the effects of several etching reagents. An interesting series of comparative electron micrographs were shown. The last paper, by Mr. J. I. Morley, of Brown-Firth Research Laboratories, was rather different in character and was concerned with the examination of metal powders in the electron microscope. The micrographs show tungsten powders produced by different methods and the effect of ball-milling on particle-size. Attention was also directed to the use of shadowing to give information about the height of particles and the profile of their upper surfaces.

In introducing these papers, Dr. Allen considered them mainly from the point of view of a metallurgist, and he also took the opportunity of referring to matters of metallurgical interest in the papers discussed at the morning session. He mentioned the $\sigma$-phase work of Mahla and Nielson, and Heidenreich's study of the carbide precipitates formed during the tempering of martensite quoted in Schwartz's paper. Etch patterns exhibited by Grivet, by Geach and Bucknell, and by Cooper and Bassett show the need for more information on the nature of the etching process if full value is to be obtained from electron micrographs. Although the interpretation has given rise to controversy, the use of the aluminium pressing method holds promise for the examination of fractured surfaces. The widely different structures which can be found in a given metallurgical specimen emphasize the need for care in basing any conclusions on a single electron micrograph.

Mr. G. L. Bailey, director of the British Non-Ferrous Metals Research Association, opened the discussion. $\mathrm{He}$ thought that while the papers in the symposium had gone far to give the metallurgist confidence in the instrument, it was not yet completely established in the field of metallurgical research. He questioned certain features in a number of the micrographs, and this had the useful effect of stimulating the ensuing discussion. M. R. Castaing, of the Office National d'Études et de Recherches Aéronautiques, Paris, described some very interesting work on the ageing of 4 per cent copper--aluminium alloy and on an aluminium alloy containing magnesium and silicon.

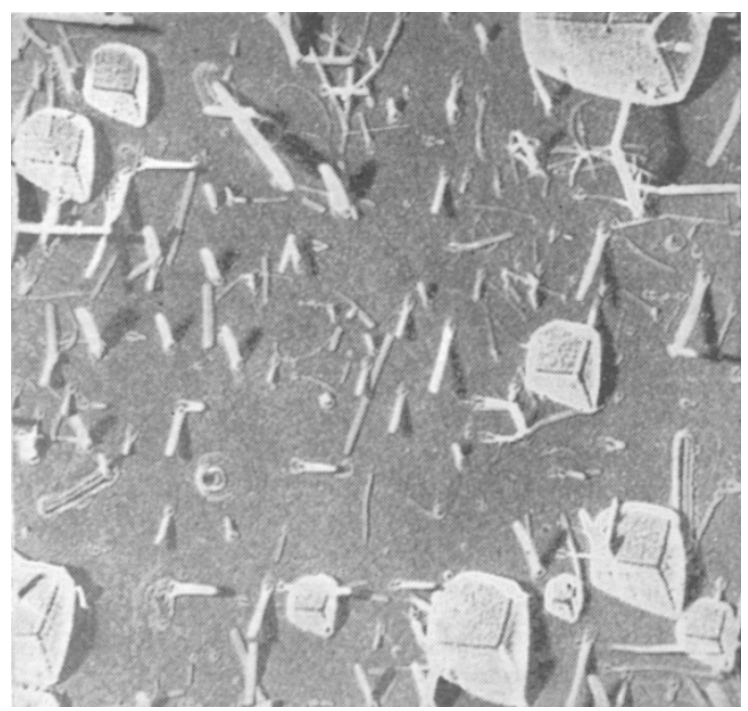

Aluminium alloy containing $0.8 \mathrm{per}$ cent magnesium, 0.5 per cent
silicon aged for $24 \mathrm{hr}$. at $250^{\circ} \mathrm{C}$. Oxide replica, chromiumsilicon aged for $24 \mathrm{hr}$. at $250^{\circ} \mathrm{C}$. Oxide replica, chromium-

The precipitation was shown at an early stage of the ageing process, and it has been established by X-rays and by the examination in the electron microscope of shadowed oxide replicas containing etch pits that magnesium silicide $\left(\mathrm{Mg}_{2} \mathrm{Si}\right)$ is precipitated in such a way that the (111) planes of the magnesium silicide lattice are parallel to the (100) planes of the matrix. Some very striking electron micrograpbs were shown (see accompanying illustration). Prof. A. Guinier made a few general remarks in which he emphasized the need for correlating optical and electron microscopy and $\mathrm{X}$-ray diffraction when studying age-hardening phenomena. He said that the electron microscope cannot observe the very thin plates of precipitate known as Guinier-Preston zones although the latter can be detected by X-ray methods. Since no zones or larger precipitate can be found by $\mathrm{X}$-rays after room-temperature ageing, he thought that ageing must have been produced in the specimens examined by Geach and Bucknell by some unknown factor such as heating in the electrolytic polishing bath. These authors agreed that the specimens may have been warmed in this way.

Some work on 4 per cent copper-aluminium alloy was described by M. A. Saulnier, of Chambéry, who has made dilatometric observations, hardness measurements and electron micrographs on the same specimens. Micrographs show the precipitation between $175^{\circ}$ and $350^{\circ}$, and an attempt has been made to relate the three sets of observations. Dr. Brown enlarged on the remarks of the rapporteur and referred in addition to some experiments on the use of methyl methacrylate as a replica material. This is polymerized on the surface of the metal, and it has been possible to show the presence of slip lines. Mr. Challice mentioned the 'orange peel' etch pattern shown on aluminium oxide replicas, and stated that he had observed a similar effect with an oxide replica of an electropolished iron specimen. Dr. Allen and Mr. Bailey were doubtful of the value of certain micrographs which show unusual etch figures (for example, the work of Cooper and Bassett), and a number of speakers referred to similar results found by other workers. The work of Chalmers and 
King on the thermal etching of silver shows that the etch patterns differ widely, depending on the crystallographic orientation of the material. Recent developments in France of scanning and emission microscopes were briefly described by Prof. Grivet. In the scanning microscope, which he is developing in collaboration with Prof. Guinier, a fine electron beam falls on the specimen, and the X-rays generated are detected in a Geiger-Müller counter. Dr. P. Coheur, of C.N.R.S., Liège, in referring to the paper by Trotter, McLean and Clews, mentioned some of his own investigations on steel specimens. He has extracted the carbides from the steels by the alcoholic iodine method, for X-ray examination. Following on this topic, Dr. Clews gave a brief account of some recent work on the tempering of martensite, comprising an electron microseope study, the examination of the etched metal surface by electron diffraction reflexion patterns, and subsequent $\mathrm{X}$-ray examination of alcoholic iodine residues. The results are in excellent agreement among themselves and with some unpublished work by Jack.

Since its inception in 1932 a very great amount of development, both of the instrument and its associated techniques, has been necessary; but from the papers presented and the discussion which followed, there is no doubt that the electron microseope has now become an important tool for the study of metal surfaces. An interesting exhibition of electron micrographs was arranged in the ante-room to the lecture theatre, and methods of replica preparation were demonstrated at the end of the meeting. C. J. B. Clews

\section{BRITISH NON-FERROUS METALS RESEARCH ASSOCIATION \\ NEW LABORATORIES}

GIR BEN LOCKSPEISER, secretary of the De$D$ partment of Scientific and Industrial Research, opened extensions to the laboratories of the British Non-Ferrous Metals Research Association on February 13. This was made the occasion of a Press conference at which some fifty representatives of the daily and technical Press were present. After an introductory talk by Sir Ben, the visitors toured the laboratories and saw work in progress. On the next three days the laboratories were open to some seven hundred guests, mostly from the technical staffs of member companies, but with many from Government departments, universities and research associations.

The new extensions were provided by reconstruction of a building destroyed during the War ; they represent for the present the concluding stage of a programme of enlargement which has been in progress for some years. The Association now has well-balanced facilities to undertake the work which the non-ferrous industry requires.

The basement of the new building contains the new metal-working laboratory, with equipment intended for the production of any special wrought metals required for use in the Association's experimental work. Such specimens have hitherto been provided by the willing and generous assistance of member companies at some inconvenience to themselves. The equipment of the metal-working laboratory includes a 500-ton down-stroke hydraulic press which can be used for extrusion or press forging; a 12 in. $\times 12$ in. rolling mill equipped with plain rolls for sheet and strip production, and grooved rolls for the production of bar material; two smaller presses (one for powder metallurgy), a drawbench, machine tools and other ancillary plant.

The first floor is devoted to the general metallurgy section, for which laboratory facilities have hitherto been inadequate. Equipment is available for the study of slag/metal and gas/metal reactions, and includes sensitive apparatus for the extraction of gases from metals and their subsequent analysis. A $7-\mathrm{kW}$. output high-frequency induction furnace is available for gas-extraction work where resistance heating is inconvenient, for oxygen determinations by vacuum fusion of metals in carbon and as a general tool in the study of equilibria at high temperatures. Studies are in progress of the copper/phosphorus/oxygen equilibrium and of properties of copper-smelting slags affecting smelting losses, a subject of interest to Commonwealth copper producers. These laboratories also contain various heat-treatment furnaces and a $20-\mathrm{kW}$. carbon resistor vacuum-furnace of the Kroll type, used, for example, in the melting of titanium : the Association is taking a very active part in research sponsored by the Ministry of Supply into the possibilities of titanium and its alloys. The general metallurgy section also includes the equipment for routine metallographic examination used in all the Association's researches. Special metallographic work has included the development of the use of diamond dust for metallographic polishing, for example, for thin coatings on hard-basis metals, and the design and construction of equipment for micro-hardness testing.

It should, however, be emphasized that these new extensions of the British Non-Ferrous Metals Research Association laboratories, important though they are, form only a part of the total space, apparatus and plant available, all of which were inspected by the visitors on the open days. In the present brief notes it is impossible to describe the entire establish. ment and the researches in progress : attention will therefore be limited to some facilities available for the application of physical and physico-chemical techniques and apparatus to the study of fundamental metallurgical problems.

In corrosion research, application is made of measurements of corrosion currents and electrode potentials, if necessary with continuous recording. Electrode potentials must be measured with instruments which take a negligible current, otherwise the electrode under observation might be polarized, yielding an untrue result. Measurements are therefore usually made with valve voltmeters or other instruments incorporating some degree of D.C. amplification. A number of instruments are in use (some adapted for continuous and multiple recording) which take maximum currents from $10^{-8}$ to $10^{-14} \mathrm{amp}$. In respect of the study of corrosion, mention may also be made of the polarograph; primarily an instrument for analytical purposes, this has been used for demonstrating differences in the character of supply waters which are not apparent from other methods of investigation. The various electro. chemical methods mentioned have been applied, for example, in the courze of investigations on the corrosion of galvanized steel and of copper. Another electrochemical technique, the measurement of voltage-current curves over very short time-intervals, is being applied to the study of the anodic film which is believed to be of importance in the mechanism of electropolishing. 